\title{
You Don't Have to Be a Scientist to Do Science
}

T 'm using my editorial bully pulpit in this issue to make a request that those of you involved ecological restoration projects take the time to write up your findings and case studies and submit them to Ecological Restoration. The reasons to do this include not only improving the practice of ecological restoration, but also improving the science.

In a recent post, New York Times blogger Olivia Judson wrote "Science is often taught as a body of knowledge-a set of facts and equations. But all that is just a consequence of scientific activity. Science itself is something else, something both more profound and less tangible. It is an attitude, a stance towards measuring, evaluating and describing the world that is based on skepticism, investigation and evidence" (Judson 2008).

These words remind us that good science, particularly good environmental science, develops out of a diverse effort. People with many different kinds of expertise contribute to building bodies of knowledge. Ecological restoration is built on the efforts of academic ecologists, sociologists, and other accredited scientists, but also practitioners of ecological restoration - a broad group that encompasses restoration contractors, city planners, government agency land managers, people working for environmental organizations, members of indigenous groups, and private landowners. These people, all of whom are experts in different ways, contribute to ecological restoration through a desire to develop an effective technology and also a recognition of the importance of evaluating and communicating their work. This journal is dedicated to these communications and to supporting the ongoing development of ecological restoration by bringing information from different types of expertise together in one forum.

In the interest of furthering the development of an effective ecological restoration science, it is worth taking a moment to reflect on how bodies of knowledge develop. There are well known examples of lay people contributing to science by providing data: the efforts of citizens to monitor stars or birds, for example, amassing quantities of information for scientists to chew on. There are inspiring models of citizen science, where members of a community pursue their own research into health or education

Ecological Restoration Vol. 27, No. 1, 2009

ISSN 1522-4740 E-ISSN 1543-4079

(O2009 by the Board of Regents of the University of Wisconsin System. concerns by collaborating with accredited scientists. The development of "alternative" approaches to medicine, agriculture, and education have arisen from creative, grassroots, and often very long-lived efforts, involving the exacting scientific work of often very driven individuals. Examples include organic agriculture, microbrewing, midwifery, and alternative educational approaches such as Waldorf schools. Sometimes these endeavors involve collaborations with accredited scientists, individuals from academic or corporate organizations, but just as often they involve dedicated practitioners working on their own with a passion for pursuing new ways of getting something accomplished, or an intense curiosity to describe an unknown process.

Passion is undoubtedly a critical ingredient, especially for scientific investigation outside the "mainstream," since would-be scientists must see their activities through a lack of financial and community support (think of today's Secretary of Agriculture stating, as Earl Butz did in the early 1970s, that organic farming was a sure route to starvation). Passion must also inspire a person to maintain careful and sometimes monotonous observation, measurement, recording, and communication of information. On the other side of that careful monitoring lie wondrous discoveries.

Frequent observations of the "gap" between science and practice reveal the challenges to building a useful body of knowledge, as well as the desire to do so. The institutions that support people in creating knowledge are, of course, very influential. As Robert Cabin (2007) pointed out with specific regard to ecological restoration, academic requirements produce results that are of profound use to academic disciplines, but not always useful to other groups. Bridging the gap between practice and research is not a problem that plagues ecological restoration alone; if we look at the respective institutional cultures of scientists, practitioners, managers, and decisionmakers, we begin to understand the processes that shape the generation and sharing of information and the barriers that make this difficult (Guston 1999).

This gap bridging represents an important horizon in the development of useful environmental sciences. As has been pointed out in this age of "postnormal science," solving today's problems requires an integrative scientific effort, one that includes experiential knowledge, and one able to entertain the complexity of different types of information (Holling 1993, Gallopín et al. 2001, Gross and HoffmannRiem 2005). Part of the answer is improved collaborations 
between scientists and practitioners (Dettman and Mabry 2008). Even more important, and of particular relevance to readers of this journal, is communication by people with their feet firmly on the ground. Science needs to hear from practitioners who, on a daily basis, monitor and communicate about a great range of types of information, including land use policy, community support, and labor management, as well as hydrology, soil chemistry, and plant ecology.

Writing up project work is often an external activity not subsidized by the professional structure. In light of the need to develop a relevant and integrated science of ecological restoration, however, and reminded by Olivia Judson that we can all be scientists, I encourage you to write up your case studies and your experiences from restoration projects and to submit them for publication. This communication is what the journal Ecological Restoration has been dedicated to ever since Bill Jordan issued the first volume in 1981 and is essential to the future of not only the practice, but also the science of ecological restoration.

Mrill Ingram

Editor, Ecological Restoration

\section{References}

Cabin, R.J. 2007. Science-driven restoration: A square grid on a round earth? Restoration Ecology 15:1-7.

Dettman C.L. and C.A. Mabry. 2008. Lessons learned about research and management: A case study from a Midwest lowland savanna, U.S.A. Restoration Ecology 16:532-541.

Gallopín G.C., S. Funtowicz, M. O’Connor and J. Ravetz. 2001. Science for the twenty-first century: From social contract to the scientific core. International Journal of Social Science 53:219-229.

Gross, M. and H. Hoffmann-Riem. 2005. Ecological restoration as a real-world experiment: designing robust implementation strategies in an urban environment. Public Understanding of Science 14: 269-284.

Guston, D. 1999. Boundary Organizations in Environmental Policy and Science: An Introduction. Science, Technology \& Human Values 26: 399-408.

Holling, C.S. 1993. Investing in research for sustainability. Ecological Applications 3:552-555.

Judson, O. 2008. Back to reality. The Wild Side New York Times blog, December 2. judson.blogs.nytimes.com/2008/12/02/ back-to-reality/ 